EL PAPEL DE LOS MUNICIPIOS EN LA SOSTENIBILIDAD AMBIENTAL

\author{
Dr. Fernando García Rubio \\ Profesor Titular de Derecho Administrativo \\ Universidad Rey Juan Carlos
}

Artículo Recibido: 15/01/2015

Artículo Aceptado: 02/02/2015

\title{
I Introducción
}

La sostenibilidad es hoy en día uno de los "mantras" que agrupan, condicionan, y encaminan toda la actividad administrativa, al menos, en las sociedades occidentales, entre las cuales, se encuentra obviamente la Española.

Ese concepto de sostenibilidad, que en buena medida tiene un origen ya con cierto abolengo, se plasmó fundamentalmente a partir de los trabajos de la cumbre de la tierra de Río de 1992, partiendo de documentos internacionales que implantándose en las diversas regulaciones nacionales y organizaciones internacionales ${ }^{2}$ como especialmente, en lo que respecta a España, en la Unión Europea, y produciendo inicialmente normas del denominado SOFT LAW, y diversas disposiciones de todo tipo, han llegado a formar un entramado que da lugar a una aplicación del concepto de sostenibilidad a los diversos aspectos de la actividad y competencia administrativa, que impregnan la totalidad de las competencias y actividades de las diferentes AAPP, y singularmente en lo que nos afecta de las entidades locales.

Ese prisma respecto a la sostenibilidad tiene una amplia concreción, y aunque fundamentalmente proviene de un ámbito ambiental se ha plasmado especialmente de igual forma en tres subconceptos que son, la sostenibilidad económica, buen ejemplo del cual es la que posteriormente citaremos ley 27/2013, de Racionalización y Sostenibilidad de la Administración Local, de 27 de diciembre, y por otra parte, la sostenibilidad social, esto es la evitación de exclusiones y creación de grupos o categorías marginales dentro de la población.

Debemos recordar que, por sostenible se entiende algo que puede mantenerse en el tiempo, y por tanto, la sostenibilidad en su conjunto indica el mantenimiento desde el ya señalado prisma o visión social, de una sociedad homogénea, en la medida de lo posible, que evite exclusiones que generen riesgo o conflicto social, igualmente el mantenimiento con los ingresos correspondientes de prestaciones y situaciones que eviten colapsos financieros y finalmente la permanencia del entorno en condiciones de uso y habitabilidad sin distorsiones que eviten su degradación e imposibilidad de mantenimiento de la vida en las condiciones actuales.

\footnotetext{
2 Así vid "Sustainable cities diversity, economic growth and social cohesión" editado por maddy Janssens, Dino Pinelli, Dafne c. Reymen, Sandra wallmal, fundación eny, enrico mattey 2009 y "The Future of sustaninable cities .Critical reflections", editado por John Flint y Mike Rako, Universidad de Bristol 2012.
} 


\section{WPS Review International on Sustainable Housing and Urban Renewal (RI-SHUR)}

De estos tres aspectos, obviamente el más importante, si hubiera alguno que destacar, es el ambiental, por la irreversibilidad de las situaciones que buena parte de las actuaciones contra el medio natural supone.

Así la sostenibilidad se ha ido incorporando progresivamente en nuestro ordenamiento jurídico siendo la plasmación más externalizada, la ley $3 / 2011$, de Economía Sostenible ,que supuso "un cajón de sastre", en el que se incorporaron disposiciones en buena parte de nuestro ordenamiento jurídico- positivo , a los efectos de introducir el citado concepto de sostenibilidad en todos sus ámbitos.

La sostenibilidad ambiental además de ser un principio general de la actuación ambiental se ha incorporado al ordenamiento jurídico tras la suscripción por parte del Reino de España y de la Unión Europea de diversos tratados internacionales ya sea la cumbre de RíO, o RíO + 20, o el compromiso de AALBORG habiendo sido incorporados, esos contenidos, a la directivas de la Unión Europea y las legislaciones Nacionales $^{3}$, especialmente como es obvio, a la legislación básica estatal, y a las legislaciones de las Comunidades Autónomas, en materia ambiental, que han trasladado el concepto desde el principio, a la legislación positiva.

Dentro del entramado administrativo-ambiental el espacio más cercano al ciudadano es el local y dentro de este el municipal ,al que en líneas generales se dirige la denominada agenda 21 para el cumplimiento de los objetivos de sostenibilidad, pero no solo las ciudades tienen ese prisma ambiental, sino que desempeñan un papel diverso ${ }^{4}$

El fenómeno municipal en España está vinculado a un generalizado minifundismo por la existencia de múltiples términos municipales, cuyos Ayuntamientos $u$ organizaciones municipales correspondientes no tienen, ni están dotados, de los suficientes medios humanos, materiales y financieros, para llevar a cabo las funciones ordinarias encomendadas a estas entidades por la legislación, de hecho esta circunstancia ha sido uno de los fundamentos de la reforma que culmina en la ya comentada anteriormente LRSAL, en cuyo texto original de anteproyecto se preveía la gestión por parte de las diputaciones de los servicios en los municipios de menos de 20.000 habitantes.

Lo que hace que en relación con la problemática de la implantación de la agenda 21 y la sostenibilidad en general, como cuestión novedosa y no prevista dentro de los servicios mínimos obligatorios recogidos por el art. 26 de la LRBRL, que necesariamente deban plantearse, dada la obligación que tienen los ayuntamientos de cumplimentar estos objetivos, de estudiar otras fórmulas para la concreta implantación y desarrollo de los criterios recogidos en la agenda 21, tras la reforma de la LRBRL por la LRSAL, estas fórmulas deben coordinarse, en su caso, por la diputación, aunque esta no descarte a los municipios.

\footnotetext{
${ }^{3}$ Sobre esta inclusión puede verse Susana Galera Rodrigo y Bernardo Hernández Bataller "CRONICA EUROPEA VI. Desarrollo sostenible, participativo, inteligente e inclusivo"Revista de derecho urbanístico y medio ambiente" $\mathrm{n}^{\circ} 286$ pags 109 a 144., 2013.

${ }^{4}$ Asi puede consultarse "Cities and the environment.New approaches for eco-societies", editado por Takashi Inoguchi, Edward Newman y Glen Paoleeto United Nations University Press, Tokyo, Nueva York, Paris, 1999.
} 


\section{WPS Review International on Sustainable Housing and Urban Renewal (RI-SHUR)}

En ese sentido debemos destacar que el sistema local español, como la mayor parte de los sistemas municipales y de régimen local de nuestro entorno, se sustenta en lo que los anglosajones denominan two-tier system ${ }^{5}$, esto es un sistema de doble instancia,, caracterizado por el municipio como entidad local básica y por una entidad local de segundo grado que con carácter general es la Provincia, (aunque existen modalidades diferenciadoras fundamentalmente en el archipiélago Balear y Canario con los Consells ${ }^{6}$, y Cabildos $^{7}$, en Cataluña con la pretendida implantación de las Veguerías $^{8}$ y en las Comunidades Autónomas uniprovinciales por la ausencia de diputaciones provinciales), que es la Provincia que se nuclea en torno a la diputación provincial o la diputación foral.

Junto a esa entidad local de segundo grado de carácter general que actúa pese a las críticas en buena medida en ausencia o incapacidad de los municipios, como entidad local prestadora de servicios y cooperadora de carácter técnico, económico y jurídico a las entidades municipales para la correcta prestación de los servicios de estos, nos encontramos con otras entidades locales de segundo grado prevista por la legislación básica estatal dispuestas en el art. 3.2 pero que son remitidas enteramente a la legislación autonómica, salvo los preceptos básicos previstos en los arts. 42, 43 y 44 de la LRBRL, con base en el art 141.3 de la Carta Magna.

Así, en este nivel intermedio supramunicipal nos encontramos ante las Mancomunidades de Municipios, las Áreas Metropolitanas y las Comarcas.

Todas esas entidades locales, ya seas municipales, provinciales o de ámbito intermedio, tienen como entidades públicas de carácter local, la obligación de implantar la agenda 21 en sus respectivas organizaciones y ejercer funciones para establecer un marco sostenible, tal y como señala Callenbach ${ }^{9}$, por lo que independientemente de la función auxiliar con respecto a los estados tienen por sí mismos que implantar dicha agenda y ejercer como núcleo esencial de la convivencia labores de ejercicio de dicha sostenibilidad desde prismas jurídicos y materiales..

\footnotetext{
5 Sobre esto vid. Alains Delcamp "Les institutions locales en Europe". Presses universitaires de France. Collección ¿Que sais je ? 1990, págs. 37 a 38 y Gerard Marcoe y Imre Verevelchy. "Size leves and functions of local government." Págs. 33 a 102 de "News trends in local government in westerm and Easterm Europe." Instituto Internacional de Ciencias Administrativas, Mayo 1993, Obra colectiva coordinada por dichos autores.

${ }^{6}$ En relación con los Consells es de obligada lectura la obra de Luis Cosculluela Montaner "El Régimen local y los cabildos insulares en el Estatuto Balear de 2007". Pags. 283 a 396 de "El gobierno local. Estudios en homenaje al profesor Luis Morell Ocaña". Iustel-Cosital. 2010. Obra colectiva coordinada por Alberto Ruiz Ojeda y Luciano Parejo Alfonso "La cuestión de la organización del gobierno y la administración insulares en la Comunidad Autónoma de las Islas Baleares" Revista de Estudios de la Administración Local núm. 291, Enero-Abril 2003, Págs. 891 a 924

${ }^{7}$ Con respecto a los cabildos desde una perspectiva general puede consultarse: Francisco Villar Rojas y Carlos de la Concha Bergillos. "El régimen especial canario". Cap LXX. Tomo IV de "Tratado de derecho municipal". $3^{a}$ edición. Iustel 2011. Obra colectiva coordinada por Santiago Muñoz Machado, más antiguo sobre el régimen específico de los Cabildos puede analizarse en Joaquín Valle Benítez "Los Cabildos insulares" Págs. 69 a 84 de Estudios de derecho Administrativo Especial Canario, dirigidos por Alejandro Nieto. Cabildo Insular de Tenerife, 1967 (reimpresión de 1994).

8 Acerca de las veguerías debe consultarse la obra de Ricard Gracia Retortillo "La veguería como gobierno local intermedio en Cataluña”. Editorial Huygens 2008. Barcelona.

${ }^{9}$ Ernest Callenbach "ecological" "rules of a sustainable Society págs. 17 a 30 de op cit. Cities and ...
} 


\section{WPS Review International on Sustainable Housing and Urban Renewal (RI-SHUR)}

\section{La competencia ambiental tras la reforma local de la "sostenibilidad"}

Como hemos indicado anteriormente, ese elemento cardinal que supone la sostenibilidad para actuación de las diversas administraciones públicas, no puede dejar al margen la administración más cercana al entorno y a la ciudadanía que es la administración local, y fundamentalmente los municipios, que conforme a lo dispuesto en el artículo 25 de la ley 7/1985, de 2 de abril, Reguladora de Bases de Régimen Local, en la redacción aportada por la ley 27/2013, de 27 de diciembre, de Racionalización y Sostenibilidad de la Administración Local, anteriormente descrita, tienen competencias en materia de medio ambiente urbano con un carácter genérico en los términos especificados por la legislación básica estatal en la materia, conforme al artículo $149.123^{\text {a }}$ ) de la Constitución, y a las legislaciones que en base a los respectivos títulos competenciales estatutarios hayan dictado en materia desarrollo de dicha legislación básica, o de las medidas adicionales de protección del medio ambiente, las diferentes comunidades autónomas.

La aprobación de la reforma de la ley 7/1985, de 2 de abril, Reguladora de Bases de Régimen Local, mediante la ley 27/2013, de 27 de diciembre, sobre Racionalización y Sostenibilidad de la Administración Local, ha supuesto un nuevo prisma en la determinación de las competencias municipales, lo que en el aspecto concreto del medio ambiente, unido igualmente a la reciente Sentencia del Tribunal Supremo de fecha 10 de junio de 2014, sobre competencias en relación con la limpieza de cauces (en este caso concreto del río Tormes, en Salamanca), en el momento del paso de los ríos por las poblaciones, nos hace propiciar unas breves reflexiones sobre el ámbito competencial de los municipios en relación con el medio ambiente urbano, el contenido de esta determinación y sus influencias sobre la ordenación urbana en su conjunto.

Así en primer lugar, la propia atribución competencial del artículo $25 \mathrm{LRBRL}$, implica necesariamente, sobre medio ambiente urbano supone una clara limitación de las funciones municipales al casco de las poblaciones, en tanto, en cuanto, el medio ambiente en suelo no urbanizable no quedaría expresamente atribuido, al menos a la legislación básica estatal, a las competencias municipales, lo cual lógicamente debe incidir sobre las normas de protección que se establezcan en los planes generales de ordenación urbana, que recuérdese, deben de incluir las medidas para garantizar la exclusión del proceso urbanizador y la conservación de esos suelos no urbanizables, cuya competencia administrativa desde el punto de vista ambiental ya no estaría atribuida a los municipios, al menos en apariencia.

Esta circunstancia supone que las competencias sobre medio ambiente sean ya, no solo concurrentes, sino, incluso confusas, entre las diversas administraciones, especialmente la que ejerza la gestión, entre las comunidades autónomas y las entidades locales, no habiéndose introducido en la LRSAL, un sistema de transición, como sí ha ocurrido con las competencias educativas, o de servicios sociales y sanitarias para la perdida de estas competencias por las entidades locales y su gestión con carácter general por las comunidades autónomas, titulares del título competencial estatutario que prevalece sobre el básico municipal. 


\section{WPS Review International on Sustainable Housing and Urban Renewal (RI-SHUR)}

En relación con esta falta de concreción competencial, debemos de traer a colación la indicada Sentencia anteriormente aludida, por medio de la cual, el Ayuntamiento de Salamanca es condenado y debe ejercer la competencia en materia de limpieza del cauce del río Tormes en su paso por el casco urbano, no siendo dicha competencia de la Confederación Hidrográfica.

Esta Sentencia que puede parecer anecdótica, nos hace enlazar con las cuestiones anteriormente referenciadas sobre la necesidad de coordinar las competencias en el ámbito ambiental desde un punto de vista urbano y todo ello en el marco de una concepción del urbanismo general en la cual, las medidas de protección sobre el medio ambiente urbano tiene un carácter esencial.

Así los argumentos de la Sala parten de analizar los arts. 23 y 24 del Texto Refundido de la Ley de Aguas $^{10}$, concluyendo que la limpieza del cauce de los ríos a su paso por zonas urbanas no es competencia del organismo de cuenca.

Ello significa, por lo que a nosotros nos interesa que dicha actividad queda fuera «de las competencias de la Administración Hidráulica sobre el dominio público hidráulico» de que habla el art. 28.4 de la Ley del Plan Hidrológico Nacional y, por consiguiente, que cae dentro del ámbito de aplicación de la regla general establecida por dicho precepto legal, a saber: que se trata de una de esas «actuaciones» genéricamente encomendadas a las Administraciones competentes en materia de ordenación del territorio y urbanismo.

El máximo intérprete de nuestro ordenamiento jurídico ordinario entiende por tanto que no asiste la razón al recurrente (Ayuntamiento) al invocar como infringido el art. 28.4 de la Ley del Plan Hidrológico Nacional. Su argumento central es que la sentencia impugnada ha interpretado erróneamente dicha norma, por entender que olvida que no cabe entender atribuidas a las Administraciones competentes en materia de ordenación del territorio y urbanismo aquellas actuaciones que competen a la Administración-Hidrológica.

Pero hay aquí una petición de principio, pues el recurrente presupuso conforme a la doctrina de la Sala que la limpieza del cauce está legalmente incluida dentro del ámbito competencial del organismo de cuenca. De aquí que no quepa afirmar que la sentencia impugnada vulnere el art. 28.4 de la Ley del Plan Hidrológico Nacional.

La otra observación es que la Sala no afirma ni niega, por exceder de su función en dicha sede, que la limpieza del cauce del río Tormes a su paso por el término municipal de Salamanca competa al Ayuntamiento de esa ciudad. Determinar cuáles sean «las Administraciones competentes en materia de ordenación del territorio y urbanismo» es una cuestión de derecho autonómico, tal y como tanto el propio Tribunal Supremo, como el Tribunal Constitucional desde las STC 61/1997, de 20 de Marzo, la 164/2001, de 3 de noviembre y la más reciente 141/2014, de 11 de septiembre ha afirmado.

\footnotetext{
${ }^{10}$ Con respecto a la legislación de aguas vid nuestra aportación "Régimen jurídico de la gestión del agua" El consultor de los ayuntamientos y los juzgados, 2010, Fernando García Rubio y la bibliografía allí incorporada.
} 


\section{WPS Review International on Sustainable Housing and Urban Renewal (RI-SHUR)}

Por tanto si la gestión y disciplina urbanística son materias de competencia netamente municipal, tanto en la legislación de Castilla y León conforme al supuesto analizado por el Tribunal Supremo, como en el resto de las CCAA, la mera limpieza de los cauces en suelo urbano será competencia municipal, al igual que ocurre en la ordenación del tráfico en dichos espacios, puesto que la administración gestora de esta materia al igual que la de los residuos es el municipio.

Partiendo de ese entorno jurídico lo cierto es que los conceptos de sostenibilidad, ambiente y entidad local, se conectan en base al concepto de competencia que es el que dará la habilitación específica para que las entidades locales actúen, legislen (reglamentariamente por supuesto), y tengan capacidades en estas materias, siendo por tanto ese nexo en relación con diversos aspectos el objeto del presente estudio.

Así a la hora de abordar esta situación, que puede ser tan amplia, vista la capacidad generalista que tienen los ayuntamientos, y que pese a la reforma de la ley de Racionalización, no ha idointeriorizada por la entidades locales que siguen prestando buena parte de los servicios que prestaban con anterioridad a la aprobación de la ley 27/2013, de 27 de diciembre LRSAL ${ }^{11}$.

En ese sentido, toda la materia ambiental local relacionada con la sostenibilidad sería imposible de analizar en un trabajo de este calado ${ }^{12}$, por lo que nos centraremos en los aspectos ambientales que mayor relación directa tienen con la sostenibilidad fundamentalmente en el ámbito local, y trataremos por una parte, los temas más candentes, y con mayor obligación, de trasposición de legislación comunitaria y de aplicación de legislación reciente española, el aspecto más vinculado a los aspectos de sostenibilidad en el entorno desde un punto de vista ambiental de los municipios, que es el de los residuos, basado en la reserva que a favor de ellos se hace de esta actividad por el artículo 86.2 de la LRBRL en la nueva redacción otorgada por la reiteradamente citada LRSAL, y las determinaciones sobre los principios de sostenibilidad en base a agrupación municipales como son las mancomunidades de municipios en torno a la figura de la agenda 21 , que es el instrumento previsto por la cumbre de Río para el desarrollo de estos principios en el ámbito local.

Esa sostenibilidad ambiental tiene en el ámbito municipal un importantísimo handicap en la movilidad, entendido esta, por la capacidad de traslación de un sitio a otro, tanto de personas como de vehículos, puesto que la vinculación que el ser humano occidental realiza al bienestar con el uso de vehículos, ha supuesto uno de los mayores contaminantes y de efectos perniciosos para el ambiente, desde el punto de

\footnotetext{
${ }^{11}$ Un estudio de la indicada ley lo tenemos en Lorenzo Mellado Ruiz "Génesis y realidad de la Ley 27/2013, de 27 de diciembre, de racionalización y sostenibilidad de la administración local: ¿una nueva reforma económica local?" CEMCI 2014 y por otro lado "La reforma del Regimen Juridico de la Administracion Local "coordinado por Juan Antonio Carrillo Donaire y Pilar Navarro Rodríguez, IEl Consultor de los Ayuntamientos, 2014 y Tomas Quintana López (director)"La reforma del Regimen local.Comentario a la ley 27/2013, de 27 de diciembre, de racionalización y sostenibilidad de la administración local", Tirant lo Blanch , 2014.
}

12 No obstante al respecto vid Iñigo Sanz Rubiales "Medio ambiente y Administración local :competencias limitadas y sostenibilidad económica “ Revista Democracia y gobierno local , n²5, segundo trimestre 2014 pags 4 a 12. 


\section{WPS Review International on Sustainable Housing and Urban Renewal (RI-SHUR)}

vista de ruidos, colapsos circulatorios y desde luego, emisión de gases contaminantes a la atmósfera.

Otro de los aspectos por lo tanto, a destacar son las capacidades que en materia de ordenación del tráfico otorga el texto refundido de la ley de vehículos a motor, tráfico y seguridad vial, a los municipios para ordenar este, lo que en vinculación a la anteriormente citada planificación urbanística establece una capacidad para una mejor movilidad dentro de una sostenibilidad ambiental.

Otro aspecto que debemos tener en cuenta, es la incorporación de las energías renovables a los municipios y las capacidades que tienen estos en el uso y promoción de dichas energías a los efectos de una autentica transformación en sentido sostenible de la actuación municipal en la vida de los ciudadanos.

Una última cuestión es la introducción de las ciudades inteligentes, o Smart Cities ${ }^{13}$, como capacidades de la tecnología al servicio de la actividad municipal y especialmente en el control ambiental y para el mejor desenvolvimiento de la vida ciudadana en un entorno sostenible. Este concepto de Smart Cities, da lugar a una concepción general de la actuación municipal, en relación, no solo con el ambiente, si no, con otras capacidades municipales para el desarrollo de sus competencias.

Partiendo de todos estos conceptos o hilos conductores hemos desarrollado un estudio general abordando esas materias de lo que vienen a ser las capacidades municipales en relación con la sostenibilidad ambiental, pero siempre circunscritas a las competencias locales.

Concepto este de competencias que partiendo de la irrenunciabilidad prevista en el artículo 12 de la ley 30/1992, de 26 de noviembre, sobre Régimen Jurídico de las Administraciones Públicas y del Procedimiento Administrativo Común, dan lugar a una serie de capacidades que en el clásico régimen jurídico vigente frente de las entidades locales municipales, mantenido por la LRSAL, supone que la lista del artículo 25 LRBRL, atribuye unos títulos sobre materias genéricas, en las cuales deberán ejercer competencias como tales, siendo su concreción obligación del legislador, estatal 0 autonómico, dependiendo de los títulos competenciales.

En ese sentido, debemos destacar que la LRSAL, ha supuesto una variación en general con respecto a las capacidades genéricas que la redacción originaria de la LRBRL, otorgaba a los municipios en materia competencial, puesto que la supresión radical del artículo 28, sobre el título general de atribución de materias y competencias y por tanto, en su caso, servicios prestados sobre cuantas cuestiones "redunden en beneficio de la comunidad local" ha supuesto una limitación de la capacidad competencial a las materias expresamente atribuidas por ley, o delegadas de forma expresa y en su caso a una posibilidad de prestación de los servicios y ejercicios de competencias, siempre y cuando los municipios se encuentren en una situación de

\footnotetext{
${ }^{13}$ Al respecto de esta materia puede consultarse a Carmen Navarro Gómez y Julio Navío Marco De qué estamos hablando cuando hablamos de Smart Cities: nuevos entornos para las políticas públicas locales" págs. 209 a 222 de Anuario de Derecho Municipal, 2013, nº 7 UAM, Marcial Pons.
} 


\section{WPS Review International on Sustainable Housing and Urban Renewal (RI-SHUR)}

sostenibilidad financiera, esto es, tengan superávit y cumplan las famosas tres reglas, de deuda, déficit, y plazo de pago a proveedores ${ }^{14}$.

Partiendo de este aspecto el estudio de las competencias ambientales, en relación con la sostenibilidad ambiental, lo realizamos como no podía ser menos, dada nuestra formación desde un punto de vista jurídico, un análisis jurídico que no pretende ser un tratado al respecto, si no, un mero enfoque partiendo de experiencias y realidades diarias, puesto que el que suscribe es funcionario de la Administración Local, y ejerce día a día, dichas actuaciones, pero con el necesario rigor que todo académico, como también es el caso del que suscribe, debe de ejercitar cuando plasma por escrito sus opiniones.

Por tanto, debemos de tener en cuenta, todas las experiencias que el día a día, de la Administración Local, va generando a los efectos de la consideración del análisis y abordaje de las materias y competencias, sobre la sostenibilidad ambiental de las entidades locales.

Por tanto, a la hora de abordar las competencias ambientales en un marco de sostenibilidad de las entidades locales, deberemos en primer lugar centrarnos en la atribución genérica de competencias ambientales prevista por la ley Reguladora de Bases de Régimen Local, y en concreto por el artículo 25 de dicha norma.

En concreto su apartado b), otorga competencias a los municipios en el medio ambiente urbano, en particular parques y jardines públicos, gestión de residuos sólidos urbanos y protección contra la contaminación acústica, lumínica y atmosférica en las zonas urbanas.

Esta competencia difiere de la anteriormente atribuida por la redacción originaria de la LRBRL, pero debemos entender que no es la única relacionada con el medio ambiente, puesto que las competencias con incidencia en el medio ambiente son muy diversas. $^{15}$

Así, sin ir más lejos el propio apartado c), sobre abastecimiento de agua potable a domicilio, evacuación, y tratamiento de aguas residuales tiene un componente esencialmente ambiental.

Igualmente la competencia del apartado g), sobre tráfico, estacionamiento de vehículos y movilidad, transporte colectivo y urbano, es como hemos señalado en esta introducción, otro aspecto con importante condición ambiental.

Así estas materias, deben ser concretadas mediante la correspondiente ley estatal o/y, autonómica al respecto. Así una primera cuestión a discernir, es que tipo ley atribuirá estas competencias, puesto que la relación de los apartados 4 y 5, en relación con el 3

\footnotetext{
${ }^{14}$ Dichas reglas son estudiadas por María Luisa Esteve Pardo, "El impacto del principio de estabilidad presupuestaria sobre los gobiernos locales", pags 153 a 172 del anuario de gobierno local 2012, obra colectiva dirigida por Tomás Font i Llovet, y Alfredo Galán Galán, "Racionalización y sostenibilidad de la administración local: ¿Es esta la reforma?" fundación democracia de gobierno local, instituto de derecho público, mayo 2013.
}

15 


\section{WPS Review International on Sustainable Housing and Urban Renewal (RI-SHUR)}

del citado artículo 25 LRBRL, no especifican si es una ley estatal o autonómica, aunque sí se adiciona en el apartado cuarto una determinación específica para los proyectos de leyes estatales, con lo cual, podía entenderse implícitamente la posibilidad de que haya atribución por ley autonómica en competencias ambientales.

Esta circunstancia debe matizarse en cuanto que el Iter parlamentario de la ley de Racionalización y Sostenibilidad de la Administración Local, 27/2013, de 27 de diciembre, introdujo mediante enmienda del Grupo Popular en el Congreso de los diputados un apartado 6 específico en el citado artículo, en el cual, se habilitaba expresamente a las comunidades autónomas para dicha atribución competencial mediante ley propia, circunstancia esta que fue eliminada mediante nueva enmienda del Grupo Popular en el Senado, lo cual implicó que la redacción final del artículo 8 de la ley de Racionalización y por tanto, de la redacción vigente de la LRBRL, quedará tal y como está.

En cualquier caso, las diversas comunidades autónomas y por todas el Decreto -ley $3 / 2014$ de la Generalitat de Cataluña ${ }^{16}$, han mantenido esa posibilidad de atribución de competencias por ley autonómica y desde luego con la expresa determinación del mantenimiento de las competencias que habían sido atribuidas anteriormente, mediante las diferentes leyes de las CCAA.

No obstante, debemos destacar, en aras de una mayor precisión que desde luego es importante en el aspecto ambiental que nos ocupa pero con carácter general en todos los ámbitos, que hay que diferenciar entre, los grupos de materias, o materias que recoge la $L R B R L$, en su redacción, con las funciones o competencias concretas que se atribuyen por las diversas leyes sectoriales y en este caso las ambientales. Así por ejemplo, la ley sobre Residuos y Suelos Contaminados, que recoge específicamente la competencia municipal en la materia con las determinaciones específicas al respecto.

Es partiendo de esa circunstancia, las competencias y las capacidades de las entidades locales, en relación con un entorno sostenible desde un punto de vista ambiental, sobre los cuales vamos a ocuparnos en estas líneas que a continuación continuamos desarrollando.

El desarrollo del denominado programa 21 se inició el 22 de diciembre de 1989 con la aprobación en la asamblea extraordinaria de las Naciones Unidas en Nueva York de una conferencia sobre el medio ambiente y el desarrollo como fuera recomendada por el informe Brundtland y con la elaboración de borradores del programa, -que como todos los acordados por los estados miembros de la ONU-,sufrieron un complejo proceso de revisión, consulta y negociación que culminó con la Conferencia de las Naciones Unidas sobre Medio Ambiente y Desarrollo, mejor conocida como Cumbre de Río, o Cumbre de la Tierra, llevada a cabo del 3 al 14 de junio de 1992 en Río de Janeiro, en donde representantes de 179 gobiernos acordaron adoptar el programa.(Entre ellos la Unión Europea y el Reino de España).

Hoy en día muchos de los miembros signatarios del programa 21 han ratificado los acuerdos y organizado sus propios programas a nivel nacional y local, siguiendo las

\footnotetext{
${ }^{16}$ Este Decreto Ley, no fue convalidado en plazo por el Parlament.
} 


\section{WPS Review International on Sustainable Housing and Urban Renewal (RI-SHUR)}

guías que para tal fin han desarrollado diversas entidades asociadas a las Naciones Unidas. Un ausente notable es Estados Unidos, país que asistió a la Cumbre de Río, pero que se abstuvo de firmar la declaración y el programa.

El programa $21^{17}$ ha tenido un estrecho seguimiento a partir del cual se han desarrollado ajustes y revisiones. Primero, con la conferencia denominada Río+5, se llevó a cabo del 23 al 27 de junio de 1997 en la sede de la ONU en Nueva York; posteriormente con la adopción de una agenda complementaria denominada Objetivos de desarrollo del milenio (Millennium Development Goals), con énfasis particular en las políticas de globalización y en la erradicación de la pobreza y el hambre, adoptadas por 199 países en la 55a Asamblea de la ONU, celebrada en Nueva York del 6 al 8 de septiembre del 2000; la Cumbre de Johannesburgo, reunida en esta ciudad de Sudáfrica del 26 de agosto al 4 de septiembre de 2002 y la más reciente nueva cumbre de Río + 20, de Junio de 2012 , celebrada nuevamente en la ciudad brasileña del 16 al 22 de junio de 2012.

Así sin perjuicio del interés de todo el programa para las colectividades locales debemos destacar los capítulos 18, 21 y 28 del documento original de la cumbre de Río sobre el programa 21, que se ocupa en primer lugar de la calidad y suministro de las aguas, materia que es un servicio mínimo obligatorio para todos los municipios en el Reino de España conforme a lo especificado en el art. 26.a) de la Ley $7 / 1985$, de 2 de abril, Reguladora de las Bases de Régimen Local, y que a su vez en cuanto al suministro está reservado en régimen de monopolio a las entidades locales, tal y como se preceptúa igualmente en el art. 86.2 de dicha norma.

Por lo que se refiere a la recogida de residuos sólidos y a las aguas residuales, (cloacales en los términos indudablemente hispanoamericanos del documento de naciones unidas), debemos destacar igual competencia a favor de los municipios como servicio reservado en los términos del indicado art. 86.2 del LRBRL, de la Ley $22 / 2011$, de 28 de julio, de residuos y suelos contaminados y el Real Decreto-ley 11/1995, de 28 de diciembre, por el que se establecen las Normas Aplicables al Tratamiento de las Aguas Residuales Urbanas, que han sido ya estudiadas en el capítulo tercero de este trabajo. Finalmente el capítulo 28 es el que se encarga de establecer ya un papel concreto de las entidades locales con respecto al cumplimiento del citado plan 21.

En concreto la Agenda 21 en su Capítulo 28 dice textualmente al respecto y como objetivos, después de justificar la importancia de las autoridades locales en esta materia del Desarrollo Sostenible o sustentable, en las Bases para la acción:

28.2)

a) "Para 1996, la mayoría de las autoridades locales de cada país deberían haber llevado a cabo un proceso de consultas con sus respectivas poblaciones y haber logrado un CONSENSO sobre un Programa 21 Local para la comunidad."

\footnotetext{
${ }^{17}$ El texto puede consultarse en "Programa 21. Un plan de acción para el desarrollo sostenible" Naciones Unidas 1992. y una descripción general en la voz "Medio ambiente urbano" elaborada por Enrique Alonso García y Demetrio Loperena Rota, dentro del Diccionario de derecho ambiental, obra colectiva dirigida por Enrique Alonso García y Blanca Lozano Cutanda, Iustel 2007.
} 


\section{WPS Review International on Sustainable Housing and Urban Renewal (RI-SHUR)}

Por otro lado con Del Riego Artigas $^{18}$, debe especificarse que la «Agenda 21 LOCAL» no es otra cosa que un plan de acción socioeconómico a la luz del Programa 21, pactado entre autoridades locales y ciudadanos de un municipio para emprender el desarrollo sostenible del mismo en toda su extensión y que se produce mediante el ejercicio de la participación más directa posible, real y efectiva de los ciudadanos en consenso con las autoridades locales representativas.

Este aspecto de la participación debe indicarse el progresivo avance en la materia de esta opción especialmente sobre los presupuestos participativos, aunque en España no se ha avanzado mucho en dicha línea.

Se ha permitido desde gobiernos firmantes del Programa 21 —haciendo dejación de su compromiso, pues quienes firmaron fueron los gobiernos, no los ayuntamientos ni otras entidades- que la Agenda 21 Local para los municipios del planeta haya sido interpretada por la asociación ICLEI que ha obviado y conculcado, absurdamente (en opinión del citado autor), la literalidad de lo prescrito en el capítulo 28 . Ha reducido jíbaramente la importancia de la participación directa de los ciudadanos a la vez que ha complicado gratuitamente su implantación con unas auditorias, diagnósticos y dictámenes previos «que ha prescrito arbitrariamente», desnaturalizando la institución y haciéndola prácticamente in factible en la gran mayoría de los municipios del planeta

Como resultado la Agenda 21 Local se ha convertido en una entelequia de la que nadie es responsable, se ha centrado absurdamente en "ciudades», obviando el mucho más amplio concepto de "autoridades locales", podemos afirmar incluso que es algo complicado y caro, que nadie sabe para qué sirve, que no obtiene resultados patentes y que ha tomado, en Europa, derroteros de huída hacia delante, como son las diversas agrupaciones de las «ciudades por el clima» «ciudades 21 » y otros sucedáneos, como en otra medida son los Smart Cities que luego abordaremos, olvidando que es una institución planetaria y de primera necesidad.

Por tanto es evidente que la adecuada implantación de la agenda 21, en su formulación actual, requiere de la implementación de fuertes medidas de cooperación intermunicipal.

La ciudad de Aalborg (Dinamarca), mantiene un censo de las entidades locales firmantes de la Agenda 21 Local, en la que España ${ }^{19}$ es líder absoluto en Europa, con 1237 entidades locales, de un total de 2.600, ahora bien teniendo en cuenta que el número de entidades locales en España es de 8.112, es evidente que existe una muy limitada adhesión a los principios de desarrollo sostenible por parte de las autoridades

\footnotetext{
18 Pelayo Del Riego Artigas "La agenda local 21. Una institución tergiversada" El Consultor de los Ayuntamientos y de los Juzgados, No 22, Sección Colaboraciones, Quincena del 30 Nov. al 14 Dic. 2008, Ref. 3697/2008, pág. 3697, tomo 3, Editorial LA LEY.

${ }^{19}$ Esa implantación ha sido posible, tal y como recoge Marta Lora-Tamayo Vallvé "Desarrollo sostenible y administración local" pags 323 a 342 de "Reforma y retos de la administración local", Marcial Pons 2007, obra colectiva dirigida por Ramón Parada Vazquez y Jose Angel Fuentetaja Pastor, y en concreto pag 399, por la aprobación del denominado Código de buenas prácticas ambientales y la guía llave del mismo, así como una aplicación informática que proporciona la FEMP
} 


\section{WPS Review International on Sustainable Housing and Urban Renewal (RI-SHUR)}

locales, pese a que indudablemente superamos en nuestro país ampliamente, el número de suscriptores al de otras naciones de Europa.

Así la carta de Aalborg, pretende realizar una implantación en el seno de la Unión Europea de los objetivos del programa 21 de Naciones Unidas, pero a diferencia de aquel, se centra tan sólo en las ciudades, y no en las "autoridades locales". No obstante debemos destacar que tanto en la primera carta de Aalborg, como en la más reciente Aalborg +10 , se ha producido una serie de adhesiones de entidades supramunicipales y que avanzan en la consecución de los objetivos.

En general sobre la sostenibilidad ambiental debemos destacar que dentro de las condiciones (denominadas) de la acción comunitaria ambiental, tal y como indican Lozano Cutanda y Alli Turrillas $^{20}$, deben destacarse las condiciones relativas a la necesidad de tener en cuenta las condiciones del medio ambiente de las diversas regiones de la comunidad así como el desarrollo económico y social de la comunidad en su conjunto del desarrollo equilibrado a sus reacciones, por lo tanto, esta circunstancia hace necesario la conversión del concepto de desarrollo sostenible en su conjunto, tal y como en su momento afirmara para el ámbito comunitario Alonso García ${ }^{21}$.

Partiendo de esas determinaciones vamos a analizar tres aspectos actuales de la sostenibilidad ambiental municipal.

\section{Energías renovables y municipios}

1. El papel de los ayuntamientos en relación con las energías renovables.

En la situación actual de crisis económica generalizada a que se ven abocados los habitantes de España derivada tanto de la crisis financiera y de deuda como del agotamiento del modelo productivo tradicional en que se basaba la economía nacional, los municipios no son una excepción en dicho marco generalizado de falta de recursos y deuda importante.

Debemos añadir junto a la crisis financiera anteriormente señalada la existencia latente ya desde las crisis del petróleo del año 1973 y 1993, la convergencia de una crisis energética por el aumento exponencial de los precios de los hidrocarburos y la escasez de éstos en las sociedades occidentales, a la cual hay que adicionar, y evidentemente, la absoluta dependencia externa de España en esta materia. La escasez y carestía de los combustibles fósiles unido (aunque no hay que negarlo con menor importancia social) a la necesidad de limitar las emisiones contaminantes de estos combustibles para disfrutar de un entorno ambiental sostenible, ha hecho que se vengan propugnando desde todos los aspectos sociales un mayor papel de las

Blanca Lozano Cutanda y Juan Cruz Alli Turrillas" Administración y legislación ambiental," Dykinson S.L. 2005, pág. 139

${ }^{21}$ Enrique Alonso García "El derecho ambiental de la Comunidad Europea", dos volúmenes, Civitas Fundación Universidad Empresa Madrid 1993. 


\section{WPS Review International on Sustainable Housing and Urban Renewal (RI-SHUR)}

energías renovables procedentes de la biomasa ${ }^{22}$, solar, eólica, maremotriz etc., así como la tradicional hidroeléctrica.

Ese tipo de energías han sido primadas, especialmente en España, desde un punto de visto geopolítico-administrativo mediante un sistema de asignación de cuotas que facilitaba y propiciaba la producción mediante estas formas, pese a su déficit de producción con respecto a los precios de mercado.

En ese sentido esa profusión de energías renovables ${ }^{23}$ ha hecho extensible a la sociedad una sensibilidad en relación con dichas energías renovables que se traduce en una actividad administrativa al respecto, derivada lógicamente del reparto competencial establecido en virtud del bloque de constitucionalidad de la Carta Magna de 1978 compuesto por las propias determinaciones constitucionales, así como los diversos Estatutos de Autonomía y las configuraciones establecidas por el art. 28.1 de la Ley Orgánica 2/1979 del Tribunal Constitucional.

A ese bloque de constitucionalidad competencial, podríamos añadir, con algún atrevimiento, que debemos incluir las funciones y competencias que las entidades locales en su conjunto pueden desempeñar en relación con el ámbito energético, conforme a las determinaciones previstas en la ley 7/1985, de 2 de abril, Reguladora de las Bases de Régimen Local, en la que se recogen toda una serie de funciones y competencias previstas en el art. 25 que indudablemente tienen una diferencia, en al menos el consumo energético y por otro lado unas funciones de usuario energético en su condición del prestador de servicio público de alumbrado) público(art. 26), que hacen necesario un estudio diferenciado de las funciones municipales en relación con esa disminución del consumo energético y del consecuente gasto que ello produce en aplicación de las determinaciones de la Ley Orgánica 2/2012, de 26 de abril, de equilibrio presupuestario y sostenibilidad financiera.

Partiendo tanto de dicha determinación general, debemos señalar que en cuanto a las funciones sobre la energía, las diversas Administraciones Públicas dividen sus competencias partiendo lógicamente de las atribuciones concedidas a la Administración General del Estado y a las Cortes Generales con su función legislativa en relación con la energía que se recogen de forma fundamental en la Ley de Ordenación del Sistema Eléctrico Nacional 54/1997, y la existencia de una organización administrativa nucleada en torno al Ministerio de Industria, Energía y Turismo, donde debemos destacar en la materia que nos afecta de energías renovables el papel del Instituto de diversificación y ahorro energético.

Por tanto, las grandes competencias sobre regulación en relación con la materia de las energías renovables las tiene atribuidas la Administración del Estado. Por otra parte debemos recordar que las Comunidades Autónomas también ejercen competencias en materia de ordenación económica en sus ámbitos territoriales y, en ese sentido

\footnotetext{
22 Sobre esta materia vid Ramón Martín Mateo "La aportación de la biomasa al aprovisionamiento energético" Administración de Andalucía: revista andaluza de administración pública, , No.60, 2005, págs. 35-48

${ }^{23}$ Un estudio de la citada materia lo tenemos en Enrique Domingo López "Régimen jurídico de las energías renovables y la cogeneración eléctrica" INAP, 2000
} 


\section{WPS Review International on Sustainable Housing and Urban Renewal (RI-SHUR)}

debemos destacar el papel no sólo como consumidores de grandes fuentes de energía y cantidades en virtud de sus competencias exclusivas, o de Sanidad, o Educación con el lógico traslado a los edificios públicos que prestan esos servicios, sino también su fomento de la diversificación energética en relación con competencias medioambientales o de planificación económica y desde luego de ordenación del territorio y así podemos llegar a las leyes de los parques eólicos aragoneses, o las determinaciones de Navarra al respecto y singularmente las leyes de Castilla-León sobre energías renovables y eficiencia energética o de Andalucía.

Por último en su papel evidente de consumidor final, pero también con algunas funciones administrativas de ejercicio de potestades al respecto nos encontraremos apenas con las Entidades Locales, especialmente los Ayuntamientos en virtud de las competencias a ellos atribuidas, anteriormente citadas de los arts. 25 y 26 LRBRL, y desde luego en sus funciones de consumidores en relación con la necesidad de contención del gasto y cumplimiento del equilibrio presupuestario previsto en el art. 135 de la C.E, conforme a la previsión de ya citada Ley Orgánica de Estabilidad Presupuestaria y sostenibilidad financiera y la situación en ese aspecto muy endeble de una gran parte de los municipios, que se han tenido que acoger a los planes de pago con los correspondientes planes de ajuste o planes financieros previstos en los Reales Decretos Leyes 4 y $7 / 2012$ y $8 / 2013$, reajustados a su vez por la ley $13 / 2014$, de 14 de julio.

Partiendo de dicha situación debemos destacar el papel de las Entidades Locales (puesto que también debemos recordar la figura de las Entidades Locales de segundo grado y singularmente las Diputaciones Provinciales con respecto a la asistencia y cooperación con los pequeños municipios), en relación con esa diversificación energética y fomento de las energías renovables.

En primer lugar, debemos recordar con Jordi Borja y Manuel Castells ${ }^{24}$ la existencia relevante de un papel local en un mundo globalizado y la necesidad de la implantación de la diversificación energética y el aumento de las diversas energías renovables para una construcción de un desarrollo sostenible, desde cada uno de los núcleos de población humano y que fundamentalmente se institucionalizan a través de los municipios, siendo más fácil la implantación desde abajo hacia arriba que al revés.

En segundo lugar, debemos señalar en relación con lo que Isabel González Ríos ${ }^{25}$ denominaba "relevante contribución" de las Entidades Locales, su papel en relación con la que algún día llegará posible liberalización real del suministro de energías y el papel del autoconsumo, puesto que la cantidad de bienes públicos, en poder de los municipios, ya sean edificios como consumidores o como posibles fuentes de generación de energía por implantación de paneles solares o uso de la biomasa de los bosques comunales, etc., tienen los ayuntamientos.

$Y$ en tercer lugar, debemos destacar el papel que tienen como actor pasivo de la implantación de las energías renovables por el gran consumo que generan los

\footnotetext{
${ }^{24}$ Jordi Borja y Manuel Castells "Local y global .La gestión de las ciudades en la era de la información," Taurus, 1998

${ }^{25}$ Isabel González Ríos "Régimen jurídico-administrativo de las energías renovables y de la eficiencia energética".Thomson Aranzadi, 2011.
} 


\section{WPS Review International on Sustainable Housing and Urban Renewal (RI-SHUR)}

municipios de energía eléctrica, esto es, como principales clientes de las compañías hidroeléctricas y así podemos señalar el alumbrado público y los propios edificios municipales y así a prestadores de servicios públicos (por ejemplo los polideportivos), o edificios administrativos, o de carácter patrimonial de muy diverso tipo.

Dejando al margen ese papel general, fundamentalmente vinculado a las funciones municipales de fomento, en su caso, mediante la figura de la ejemplaridad de la prestación local, como en relación con el carácter igualmente ejemplarizante de su reducción del consumo en los servicios propios, debemos destacar el papel como Administraciones Públicas de las entidades locales.

En ese sentido debemos recordar que los municipios, como tales, son organizaciones administrativas y por tanto, siguiendo a Jordana de Pozas ${ }^{26}$ tienen tres grandes finalidades en su acción: la de policía administrativa, la de fomento y la de servicio público.

En dicha línea, debemos destacar, tal y como en su momento teorizara Villar Palasí ${ }^{27}$, la existencia de una cuarta teórica función o actividad administrativa, que sería la industrial, pero debemos indicar que conforme a las determinaciones de la Ley de Racionalización y Sostenibilidad de la Administración Local 27/2013, de 27 de diciembre, difícilmente los ayuntamientos que no se hallen o encuentren en equilibrio presupuestario, salvo para su consumo privado podrán dedicar funciones a esa actuación, puesto que la supresión radical del art. 28 de la Ley Reguladora de Bases de Régimen Local y la modulación de los arts 85 y 86 por las variaciones operadas en la citada ley básica mediante la indicada Ley de Racionalización y Sostenibilidad, hace que sólo escasos municipios puedan propiciar actuaciones de carácter industrial en materia energética.

2.-El papel de policía administrativa en relación con las energías renovables de los ayuntamientos.

Partiendo de este panorama de la actividad administrativa debemos destacar que los ayuntamientos tienen funciones en relación con el mundo de las energías renovables otorgados por las diversas legislaciones estatal y autonómica en materia de regulación mediante el ejercicio de su potestad reglamentaria recogida en el art. 4 de la LRBRL en materia de inspección en relación con esas regulaciones, ya sea las propias municipales o incluso mediante el ejercicio por delegación o de colaboración interadministrativa de la verificación del cumplimiento de condiciones legales 0 reglamentarias establecidas por otras Administraciones, el ejercicio igualmente de la potestad sancionadora recogida nuevamente por el art. 4 de la LRBRL en función del carácter ejemplificador que tiene el derecho sancionador con respecto al cumplimiento de las determinaciones legales y reglamentarias por parte de los particulares y finalmente unas funciones de control preventivo en la intervención de la actividad de los particulares recogidas en los arts 84 y 84 bis de la LRBRL fundamentalmente

\footnotetext{
${ }^{26}$ Luis Jordana de Pozas "El problema de los fines de la actividad administrativa". Revista de administración pública, , $\mathrm{N}^{\circ}$ 4, 1951, págs. 11-28

${ }^{27}$ José Luis Villar Palasí “ La actividad industrial del Estado en el Derecho administrativo”. Revista de administración pública, , No 3, 1950, págs. 53-13
} 


\section{WPS Review International on Sustainable Housing and Urban Renewal (RI-SHUR)}

mediante el sometimiento previo a licencia o los actos de control posterior de verificación de las condiciones necesarias de implantación de actividades, obras y servicios, así como sus funciones de homologación o verificación del cumplimiento de las condiciones de diversos tipos de aparatos y tecnologías.

Un segundo ámbito genérico de actuación de los municipios en relación con las energías renovables es el del fomento administrativo y, en ese sentido el fomento es la propiciación de objetivos mediante la intervención directa a través de técnicas como pueden ser las subvenciones para la implantación de energías renovables, como fue la clásica del Ayuntamiento de Madrid en el período 1989-1995 de sustitución de las calderas de carbón por otras menos contaminantes fundamentalmente de gasóleo y eléctricas.

Por otro lado el otorgamiento de premios a la implantación de conductas compatibles con el ambiente de implantación de energías renovables y finalmente dentro de ese ámbito del fomento de dichas energías renovables en el espacio municipal, el otorgamiento de bonificaciones tributarias para las instalaciones y uso de las energías renovables dentro de los ámbitos tributarios municipales, tal y como ha propiciado la Asociación Nacional de Municipios de Energías Renovables, al amparo de las bonificaciones tributarias que se otorgan a los bienes de interés cultural especiales, tal y como se recoge en la Ley Reguladora de las Haciendas Locales aprobada en su Texto refundido por Real Decreto Legislativo 2/2004, de 5 de marzo.

Un tercer y último aspecto de la actividad administrativa genérica, en relación con la implantación de las energías renovables es la derivada de las funciones de servicio público y así en ese sentido debemos destacar que ese servicio público hasta que se implante efectivamente, la Ley de Racionalización y Sostenibilidad de la Administración Local, tiene un carácter amplio vinculado a la determinación de la redacción originaria, art. 25.3 de la Ley $7 / 85$ de 2 de abril Reguladora de las Bases de Régimen Local de posibilidad de implantar cuantos servicios redunden en beneficio de la comunidad vecinal pero que tendrá una clara variación tras la incorporación de dicha Ley al ordenamiento jurídico, para los municipios que tengan una deuda pública o un déficit presupuestario que impidan el desarrollo de nuevos servicios al amparo de dicho título competencial.

En cualquier caso sigue siendo una competencia de servicio público obligatorio de cualquier ayuntamiento el prestar un alumbrado público, por lo tanto, siendo necesario suministrar energía para dicho alumbrado, parece evidente que la implantación de fuentes de suministro de energía de carácter renovable y propio municipal mediante producción propia, o en régimen de colaboración con entidades dedicadas a las energías renovables, es una posibilidad más que evidente que si no puede ser considerada un servicio público en su integridad, si una parte integrante esencial de éste.

\section{La regulación municipal en materia de energías renovables.}

Debemos destacar que las funciones de regulación como parte esencial del ejercicio de la policía administrativa local, debe circunscribirse, como es lógico, al ámbito competencial de las entidades locales, tal y como se desprende de la determinación 


\section{WPS Review International on Sustainable Housing and Urban Renewal (RI-SHUR)}

del art. 62.2 de la Ley 30/1992, de 26 de noviembre, sobre Régimen Jurídico de las Administraciones Públicas y el Procedimiento Administrativo Común, que sanciona con nulidad de pleno derecho las normas que vulneren el principio de competencia y de jerarquía normativa.

Por tanto, en ese aspecto las Entidades Locales tendrán un carácter regulador subordinado a las leyes estatales y autonómicas y a los Reglamentos de ambas Entidades, el Estado y cada una de las diferentes Comunidades Autónomas.

Partiendo de ese ámbito general sí debemos destacar la existencia de un cierto espacio para la reglamentación local en materia de energías renovables, tanto por un lado en relación con las propias edificaciones y servicios, puesto que debemos recordar la distinción clásica de la potestad reglamentaria local entre ordenanzas, vinculadas a las normativas que regulan las potestades hacia los ciudadanos con carácter general ad extra y reglamentos ${ }^{28}$, esto es, las normas municipales que se ocupan de la organización de servicios o cuerpos internos de los municipios (cuerpo policial, bomberos o los servicios de transporte urbano de viajeros, por ejemplo).

En ese sentido debemos recordar que dentro del ámbito de la reglamentación municipal tiene especial importancia en relación con el control de la implantación de las energías renovables y la eficiencia energética las determinaciones del código básico de la edificación, el denominado Código Técnico de la Edificación previsto por la Ley de Ordenación de la Edificación 38/1999 y que fue aprobado por Real Decreto 314/2006, en donde se recogen en sus apartados h), e) punto 4 y 5 una serie de determinaciones al respecto.

Estas circunstancias nos hacen enlazar esa función reglamentadora municipal con el mundo del urbanismo, principal ámbito de desenvolvimiento de las competencias locales en relación con la propia concepción del urbanismo como lo propio de la ciudad (urbs, en latín) y fundamentalmente con el principal ámbito de regulación que es la norma por excelencia de un Ayuntamiento (recuérdese que la cuestión de confianza del Alcalde se puede presentar tan sólo por escasísimas circunstancias, las Ordenanzas Fiscales, el Presupuesto y la aprobación del Plan General de Ordenación Urbana), que es el Plan General de Ordenación Urbana, en el cual tiene que incorporarse conforme a diversas leyes de las Comunidades Autónomas, unas normas urbanísticas del Plan. Por lo cual los municipios en dichas normas urbanísticas del Plan General de Ordenación Urbana ,así como las diversas normas del planeamiento de desarrollo, ya sean Planes Parciales, Especiales o Estudios de Detalle puede establecer la exigencia del cumplimiento de unos criterios de sostenibilidad.

Igualmente se pueden exigir mediante las normas urbanísticas de cada uno de los planes, unas determinaciones en relación con el diseño de las edificaciones, así como los sistemas generales y los locales que tengan carácter de sostenibles en cuanto a la facilitación de implantación de energías renovables y disminución de consumos energéticos.

\footnotetext{
${ }^{28} \mathrm{Al}$ respecto vid Antonio Embid Irujo “La potestad reglamentaria de las entidades locales”, Iustel , 2010
} 


\section{WPS Review International on Sustainable Housing and Urban Renewal (RI-SHUR)}

Ya hemos hecho referencia al papel clave del alumbrado del municipio en relación con el desempeño o desarrollo de esos consumos energéticos y sus posibles limitaciones, siendo este un servicio obligatorio conforme al art. 26.a) de la LRBRL en todos los municipios, por tanto, tiene igualmente un papel las Diputaciones Provinciales a la hora de auxiliar y cooperar con los diversos municipios en la consecución del cumplimiento de este fin, puesto que el art. 36 de la LRBRL atribuye fundamentalmente a las Diputaciones esas funciones de auxilio técnico, económico y de cooperación para la prestación de los servicios obligatorios.

Así los municipios deben de cumplimentar en esas funciones de regulación el cumplimiento del Reglamento de Instalaciones Térmicas (RITE) regulado por el Real Decreto 238/2013(que modifica el texto original del RD 1027/2007) y el Reglamento de Certificación Energética de edificios, regulado por el Real Decreto 235/2013, así como en su caso la sujeción de los planes municipales a la planificación territorial acordada por la Comunidad Autónoma, en el caso de que existiera.

Por tanto, el Plan General se puede convertir en si mismo en un gran valedor de las energías renovables, no obligando al uso de ellas, en tanto en cuanto no existe una habilitación al respecto que la Ley del Sistema Eléctrico Nacional no recoge, sino como ordenador de las condiciones para implantación de estas instalaciones, evitando o removiendo los obstáculos que pudieran generarse para el cumplimiento de dichas funciones. Por ejemplo las placas solares de los tejados o similares, puesto que un plan puede no facilitar pero si puede bloquear la implantación de estas energías por medidas o limitaciones de carácter estético o arquitectónico. Así dentro de la reglamentación debemos destacar la existencia ya comentada de ordenanzas, como por ejemplo la de Rivas-Vaciamadrid de 28 de octubre de 2010 sobre eficiencia energética y de las energías renovables o la de Murcia de 11 de marzo de 2008.

Así debemos destacar que la Asociación Nacional de Municipios con instalación de energías renovables se constituyó el 21 de febrero de 2008, lógicamente como Asociación de derecho privado en base a la Disposición adicional quinta de la ley Reguladora de Bases de Régimen Local a la cual se puede considerar como asociaciones de entidades de derecho público, que lógicamente deben de limitarse a los aspectos previstos en el artículo 22 de la Constitución, y en la ley orgánica 1/2002 de Asociaciones de desarrollo de dicho derecho de Asociación.

Esta Asociación Nacional de municipios e instalaciones de energía renovables aglutina a municipios, en cuyos términos municipales se recogen instalaciones produciendo energías renovables, tanto eólica, fotovoltaica, térmica, etc., y cuyo objetivo fundamental constituye la defensa de los intereses generales particulares de los ayuntamientos que tienen dicho tipo de instalaciones en su término municipal.

Uno de sus principales objetivos, tiene una lógica defensa de los intereses recaudatorios de los ayuntamientos puesto que, el Real Decreto 417/2006, de 7 de abril, que regula los bienes inmuebles de características especiales, los famosos bíceps, entre parques eólicos, supuso un grave perjuicio para los ayuntamientos, de hecho, la sentencia del Tribunal Supremo de 3 de mayo de 2007, confirmó la nulidad parcial de dicho Reglamento de desarrollo de la ley del Catastro. 


\section{WPS Review International on Sustainable Housing and Urban Renewal (RI-SHUR)}

Así la capacidad de reglamentación municipal de estas materias es muy limitada, aunque pueden encontrarse aspectos sobre la reglamentación interna de los propios servicios municipales, y como el caso del reglamento municipal sobre incorporación de sistemas de captación y aprovechamiento de energía solar térmica de los edificios de la ciudad de Valladolid(Boletín oficial de la provincia de Valladolid de 15 de febrero de 2005), que fue aprobado por el Pleno de la Corporación el 21 de diciembre de 2004.

Desde un punto de vista de Fomento debemos destacar la labor del Ayuntamiento de Vitoria y del de León.

En cualquier caso, las instalaciones propias en fórmula de actuación económica que conforme a la actual artículo 86.2 de la LRBRL, sin que el municipio fuera sostenible financieramente en los términos del artículo 7.2, de dicha norma, tras la ley de Racionalización y Sostenibilidad de la Administración Local, son de muy diverso tipo, puesto que junto a los parques eólicos, o las instalaciones de energía solar de edificaciones municipales podemos encontrarnos la capacidad para actuar en relación con la biomasa, especialmente en relación con municipios rurales.

Además de este uso de la capacidad económica empresarial y a través de esta materia, lo lógico es que el aspecto de la energía renovable se vincule al ahorro y eficiencia energética, y el combate del cambio climático, en el sentido de avanzar hacia una gestión energética más sostenibles y así, podemos destacar, el plan de usos sostenible de energías y prevención del cambio climático aprobado en 2008 por el ayuntamiento de Madrid en el marco de la estrategia de calidad del aire desde el cual se impuso en acciones de ahorro y eficiencia energética incluso estableciendo el cierre obligatorio de los edificios a las 17:00 horas.

En este ámbito el ayuntamiento de Madrid aprobó la Ordenanza sobre captación de energía solar para usos térmicos, siendo las edificaciones y construcciones afectadas cuando se trate de obras de nueva planta, sustitución, o reestructuración de carácter general ,o total de edificios existentes, así como obras de ampliación que en sí mismo supongan la nueva construcción de un edificio independiente dentro de la misma parcela, y que el uso de la edificación le corresponda a algunos de los previstos en el artículo tercero de la propia ordenanza, que son, los residenciales, dotacionales de servicios públicos, dotacional de administración pública, dotacional de equipamiento de las categorías educativo cultural, salud y bienestar social, dotacional deportivo, terciarios en todas sus clases, industrial de clases y servicios empresariales, y cualquier otro industrial que comporte su agua a la red sanitaria, y cualquier otro uso que implique la utilización de agua caliente sanitaria.

En todo caso, en todas estas ordenanzas se prevé el paso Técnico, y así la exposición del artículo quinto de la madrileña, sobre la mejor tecnología disponible, puesto que hace una referencia genérica a la mejor tecnología disponible, en cuanto a la aplicación, a los efectos de permitir la permanente adaptación de las instalaciones la captación solar objeto de la citada ordenanza en Madrid, para los avances tecnológicos correspondientes, solamente se deberá tramitar la modificación de licencia cuando así lo exijan las ordenanzas especial de la tramitación de licencias, y cuando dicha modificación de licencias se requiera de oficio por parte del ayuntamiento se indicará las alteraciones existentes y se motivará el requerimiento, 


\section{WPS Review International on Sustainable Housing and Urban Renewal (RI-SHUR)}

lógicamente como cualquier actuación que se realice por parte de la administración con carácter favorable a los particulares el someterse a una nueva licencia lo es debe realizarse dicha motivación, conforme al artículo 54 de la ley 30/1992, de noviembre sobre Régimen Jurídico de las Administraciones Públicas y del Procedimiento Administrativo Común. En la ordenanza Madrileña se realiza en el artículo 7.2, una revisión señalando que se considerará adecuada " a los pliegos oficiales de condiciones técnicas del instituto de dosificación y ahorro energético, igualmente se establece determinación sobre protección del paisaje y circunstancias excepcionales, en cuanto a las empresas instaladoras, lógicamente se exige la cumplimentación del RITE, esto el reglamento de instalaciones térmicas de edificios, e igualmente el deber de conservación prevista en el artículo noveno del texto refundido de la ley de suelo.

\section{Las Ordenanzas locales de residuos, El papel de la regulación municipal sobre las basuras}

Como ya hemos indicado uno de los principales aspectos de la sostenibilidad ambiental en materia municipal es la referida a los residuos, tal y como se plasma en la agenda 21.

Con carácter previo debe indicarse que la ley de 22/2011 de 28 de julio de residuos y suelos contaminados atribuye como competencia local

1․ Elaborar programas de prevención y de gestión de los residuos de su competencia.

$2^{\circ} \quad$ Gestionar los residuos comerciales no peligrosos y los residuos domésticos generados en las industrias en los términos que establezcan sus respectivas ordenanzas, sin perjuicio de que los productores de estos residuos puedan gestionarlos por sí mismos en los términos previstos en el artículo 17.3, de la ley de Residuos y Suelos Contaminados, cuando la entidad local establezca su propio sistema de gestión podrá imponer, de manera motivada y basándose en criterios de mayor eficiencia y eficacia en la gestión de los residuos, la incorporación obligatoria de los productores de residuos a dicho sistema en determinados supuestos.

3.- $\quad$ A través de sus ordenanzas, obligar al productor o a otro poseedor de residuos peligrosos domésticos o de residuos cuyas características dificultan su gestión a que adopten medidas para eliminar o reducir dichas características o a que los depositen en la forma y lugar adecuados.

4. Realizar sus actividades de gestión de residuos directamente o mediante cualquier otra forma de gestión prevista en la legislación sobre régimen local. Estas actividades podrán llevarse a cabo por cada entidad local de forma independiente 0 mediante asociación de varias Entidades Locales.

Cabe reseñar que una fuente del derecho de residuos, no suficientemente tenida en cuenta por los estudios específicos sobre residuos pero que en el marco de este trabajo no podemos soslayar, es la recogida por la regulación específica de cada municipio, conforme a las competencias atribuidas por el art 25 de la ley $7 / 1985$, de 2 


\section{WPS Review International on Sustainable Housing and Urban Renewal (RI-SHUR)}

de abril, reguladora de las bases del régimen local, que en virtud de la potestad reglamentaria atribuida a los municipios por el art $4^{\circ}$ de la citada $L R B R L$, son tramitadas, aprobadas y publicadas por estos conforme a los arts 49 y 70.2 de dicha ley básica.

Las ordenanzas locales en materia de residuos tienen mayor relevancia que en otros campos de regulación local. No se limitan a ser un mero complemento de la legislación estatal o autonómica sino que regulan ex novo muchos aspectos a los que aquéllas no pueden llegar (residuos admisibles en los servicios municipales, pretratamientos permitidos o exigidos, forma de presentación de los residuos para la recogida municipal, organización de la recogida, etc.).

Las Ordenanzas Locales son, por ello, instrumentos de ordenación imprescindibles en la gestión de los residuos urbanos. Pero, además, debe advertirse que las entidades locales pueden superar las condiciones de gestión previstas en la normativa estatal o autonómica. La STJCE de 13 de julio de 1989, Enichem base y otros contra Comune di Cinisello Bálsamo, admitió la prohibición municipal de proporcionar y vender bolsas de plástico a los consumidores para el traslado de las mercancías compradas. Salvo las destinadas a la recogida de residuos. Posibilitando, por tanto, que las ordenanzas locales establezcan medidas sobre la gestión de residuos más estrictas que las previstas en las disposiciones estatales sí responden a los objetivos de la normativa comunitaria.

Por ejemplo la ordenanza de recogida, limpieza y retirada de residuos y para de protección de espacios públicos del ayuntamiento de Colmenar Viejo, establece una distinción entre elementos de recogida obligatoria, para los cuales recoge los desechos de la alimentación del consumo doméstico, producido por los ciudadanos en sus viviendas, las cenizas de calefacción doméstica e individual, los residuos procedentes del barrido de las aceras efectuadas por los ciudadanos, los residuos asimilables a los domésticos, la broza de la poda de árboles y del mantenimiento de las plantas, siempre que se entregue troceada y en una bolsa, los envoltorios, envases y embalajes, y otros residuos sólidos producidos en locales comerciales, las materias residuales producidas por actividades de servicios comerciales industriales de características similares a los desechos domiciliarios, los residuos producidos por el consumo de bares, restaurantes y demás establecimientos que expidan productos alimentarios cocinados o en los que se realicen consumiciones de cualquier clase. Así mismo los producidos en supermercados $u$ otros servicios y establecimientos similares.

Los residuos de consumo en general producidos en residencias, hoteles, colegios y otros establecimientos públicos o abiertos al público, y los residuos originados por actividades de mercados municipales, pero en ningún caso, se incluye en la recogida domiciliaria los materiales de desecho, cenizas, escorias producidas en fábricas, talleres, almacenes, productos de instalación y tratamientos de residuos, los neumáticos, los procedentes de explotaciones agrícolas y ganaderas, en general aquellos que por los criterios de presentación, volumen, peso, cantidad del libramiento diario, contenido de humedad, no puedan ser objeto de recogida domiciliaria según los servicios técnicos del ayuntamiento, igualmente quedan excluidos de este régimen de 


\section{WPS Review International on Sustainable Housing and Urban Renewal (RI-SHUR)}

recogida, los residuos clínicos contaminantes, los animales muertos, las tierras y escombros, todos ellos regulados por su propia normativa.

Debemos destacar que por el gran volumen, estos suponen en la sociedad desarrollada y consumista en que nos movemos, su gestión es su problema fundamental para la consecución de un desarrollo sostenible, como persigue la Agenda 21.

En dicho sentido cabe indicar, que muy escasos municipios pueden mantener vertederos del tamaño que su desarrollo y consumo ha generado, por lo que se articula la necesidad de implantar dicho tipo de vertederos en zonas de fácil conexión con los diferentes municipios y que además tengan las debidas garantías en cuanto a lejanía de poblaciones, seguridad e higiene.

Pero este problema ya tradicional y que había generado la cooperación intermunicipal y municipal con otras entidades, ha supuesto un nuevo reto en una progresión indispensable ya de agrupación intermunicipal con respecto a la obligación del tratamiento de residuos, que no supone el mero almacenaje, sino como ya indicábamos el tratamiento y en su caso valorización de los residuos a los efectos de cumplimentar la sostenibilidad auspiciada desde la Cumbre de Río.

De hecho la nueva redacción de la LRBRL tras la LARSAL, incorpora de forma efectiva ese servicio de "tratamiento" para los residuos.

Ejemplo de esta articulación lo tenemos en la Comunidad de Madrid donde se han constituido cuatro mancomunidades para la gestión de residuos siendo la primera la denominada mancomunidad del Este, cuya sesión constitutiva tuvo lugar el 14 de diciembre de 2006 y sus Estatutos fueron publicados en el Boletín Oficial de la Comunidad de Madrid de 27 de noviembre de 2006 recogiendo en su art. 5:

"La Mancomunidad tendrá por objeto la prestación del servicio de gestión de los residuos, y en especial el tratamiento, valorización energética y eliminación de los RSU generados en los términos municipales de los municipios que integran la mancomunidad, en orden a la debida protección del Medio Ambiente, fomentando, en su caso, el reciclaje y el aprovechamiento de tales residuos mediante la adecuada recuperación de los recursos contenidos en ellos.

2.- La competencia de la Mancomunidad podrá extenderse a otros fines comprendidos dentro de las competencias que la legislación sobre residuos disponga como competencia municipal, y cuya realización conjunta interese a los miembros agrupados, siempre que exista mayoría cualificada de dos tercios del número total de votos de la Asamblea General.

3. - La Mancomunidad ejercerá su actividad y prestara sus servicios, de acuerdo con las formas de gestión de los servicios prevista en la legislación vigente de aplicación."

Ese papel se vincula no solo a la recogida, sino la valorización y eliminación, con un importante papel de los sistemas integrados de gestión, o SIG's, dentro 


\section{WPS Review International on Sustainable Housing and Urban Renewal (RI-SHUR)}

de lo que Alenza García ${ }^{29}$, denomina concepción sistemática de la gestión de residuos.

\section{Entidades locales y eficiencia energética ${ }^{30}$}

Las anteriormente apuntadas competencias municipales y por tanto las referidas a la materia de eficiencia energética, si pudieran existir, han sido claramente afectadas como ya hemos apuntado por la ley 27/2013, de 27 de diciembre, sobre Racionalización y Sostenibilidad de la Administración Local, norma que ha supuesto en buena lógica una limitación de la capacidad genérica que antiguamente otorgaba la legislación de Régimen Local a las Entidades Locales para actuar en cuantas materias redundaran en beneficio de la comunidad.

Partiendo de dicho hecho, lo cierto es que los municipios tienen competencias en materias concretas vinculadas al artículo 25 de la LRBRL, y a los servicios públicos que deben de prestar, entre ellos por ejemplo, el de alumbrado público, en vías, parques, calles, etc., y desde luego, en el alumbrado de sus propios edificios, sean de servicios públicos hacia los ciudadanos, o los servicios públicos staff frente a la propia organización municipal.

Partiendo de ese aspecto, debemos recordar que la directiva de eficiencia energética centra especial importancia en las entidades públicas, si es bien cierto, que las entidades locales y regionales las recoge en apartados subsidiarios y en políticas generalistas y no en determinaciones directas de obligación de reponer edificaciones mediante consumos energéticos casi nulos.

Así por un lado, debemos destacar, el carácter frente a la materia de eficiencia energía que tienen las corporaciones locales, por una lado de prestador de servicio, y por otro lado, de consumidoras, junto a ello lógicamente la aplicabilidad o no, del texto refundido de la ley General de Defensa de los Consumidores y Usuarios, aprobada por Real Decreto Legislativo 1/2007, de 16 de noviembre.

Dentro del panorama anteriormente descrito de profunda crisis económica y carencias de recursos de las EELL, el papel de estas en la materia que no ocupa.

Por tanto debemos plantearnos en el marco actual con respecto a la eficiencia energética de las entidades locales, un escenario con precios de energía en alza y con previsibles subidas, un segundo escenario vinculado al artículo 135 de la Constitución, y a la ley Orgánica 2/2012, de Estabilidad Presupuestaria y Sostenibilidad Financiera, con una necesidad de reducir los costes permanentes entre ellos los energéticos, a los efectos de cumplir los objetivos de Estabilidad Presupuestaria, y un tercer ámbito, vinculado a la Directiva de Eficiencia Energética, que posteriormente desarrollaremos. En ese sentido, es muy raro, que dados los costes laborales y organizativos que

\footnotetext{
${ }^{29}$ Jose Francisco Alenza García "Aspectos jurídicos de la regulación de los residuos sólidos urbanos" pags 317 a 344, de la obra colectiva dirigida por Diego José Vega Jurado "El medio ambiente urbano", CEMCI, 2003 y en concreto pag 326

${ }^{30}$ Un estudio monográfico sobre la materia lo tenemos en el libro colectivo García Rubio, Fernando y Mellado Ruíz, Lorenzo(coordinadores) ’’Eficiencia energética y derecho” Dykinson 2013.
} 


\section{WPS Review International on Sustainable Housing and Urban Renewal (RI-SHUR)}

supone la prestación por medios propios de estos servicios de eficiencia energética, y la falta de capacidad técnica y logística que muchos municipios tienen, hacen muy difícil que se opte por dicha prestación propia máxima tras la práctica imposibilidad de crear entes instrumentales desde la LRSAL. Por lo que, debemos de tener en cuenta, la posible existencia de contratos energéticos, distinguiendo en este ámbito dos grandes modelos, por un lado, los de mero suministro energético, que no es en sí mismo un contrato de suministro por las disfuncionalidades del mercado, puesto que la competencia es muy limitada, por no decir casi nula, y por otro lado, los contratos de eficiencia energética, en ese sentido, el gran parámetro de importe que pueden diferenciar unos contratos de otros es el de la inclusión o no del alumbrado público por su volumen.

Por otro lado debemos destacar, el posible autoconsumo de las entidades locales con respecto a generación propia, incorporando energías renovables o no cuestión sobre la que profundizaremos más adelante, y en un tercer lugar los servicios energéticos a prestar por el municipio, en primer lugar, como ya indicábamos el de alumbrado, en segundo lugar los edificios, en tercer lugar la existencia o no de concesiones administrativas, otras propias del municipio, y en cuarto lugar la pura eficiencia energética, esto es, la reducción de consumo, el mantenimiento con garantía total, las prestaciones que el IDAE, recoge como P1,P2, P3, y P4.

Aquí, debemos tener en cuenta, los aspectos vinculados al pago y coste de la energía realizados por el Real Decreto Ley 8/2013, que intentan evitar el oligopolio y fomentar nuevamente la eficiencia.

Partiendo de ese aspecto, la contratación o no de servicios energéticos puede tener un único criterio económico para la adjudicación, conforme al artículo 155 del Texto Refundido de la Ley de Contratos, del sector público, aprobado por Real Decreto Legislativo $3 / 2011$, de 14 de noviembre, o su sometimiento a criterios ambientales, con limitaciones como por ejemplo la procedencia de energía, si es de combustibles fósiles o no, etc., la forma de entrar en la red etc.

En ese aspecto debemos destacar, el importante coste de la energía, y la Sentencia del Tribunal Supremo de 16 de mayo, de 1997 (la ley 6544), y el hecho de que no cabe recoger en el TRLCSP reglas especiales, puesto que no existen para este tipo de contratos.

En cuanto a la directiva sobre eficiencia energética regulada por la directiva 2012/27/UE, de 25 de octubre, con los antecedentes de la derogada directiva 2006/32 y las modificadas directivas 2009/125/CE y la 2010/30/UE, debemos destacar la existencia de obligaciones específicas del sector público que se recogen de forma expresa en el Real Decreto 235/2013, de certificación energética de los edificios, y el Reglamento de Instalaciones Técnicas de edificios.

En ese sentido, se establece como ya hemos dicho, que para la Administración del Estado, la necesidad de renovación cada año del 3\%, de la superficie total de los edificios con calefacción y, o sistema de refrigeración.

Por otro lado, debemos recordar que el artículo 85 de Economía Sostenible establece: 


\section{WPS Review International on Sustainable Housing and Urban Renewal (RI-SHUR)}

\section{Artículo 85 Ahorro energético de las Administraciones Públicas}

1. Todas las Administraciones Públicas, en el ejercicio de sus respectivas competencias, incorporarán los principios de ahorro y eficiencia energética y de utilización de fuentes de energía renovables entre los principios generales de su actuación y en sus procedimientos de contratación.

2. La Administración General del Estado y sus Organismos públicos vinculados dependientes, las entidades gestoras y servicios comunes de la Seguridad Social, las sociedades mercantiles estatales definidas en la Ley 33/2003, de 3 de noviembre, de Patrimonio de las Administraciones Públicas, las fundaciones del sector público estatal definido en la Ley 50/2002, de 26 de diciembre, de Fundaciones y las demás entidades de derecho vinculadas o dependientes de la Administración General del Estado o de sus Organismos públicos, establecerán programas específicos de ahorro y eficiencia energética y de utilización de fuentes de energía renovables que, con carácter general, anticipen el cumplimiento de los objetivos generales fijados con el horizonte 2020, de modo que, de acuerdo con el Plan de Ahorro y Eficiencia Energética, se alcance en 2016 el objetivo previsto de un ahorro energético del 20 por ciento respecto al escenario tendencial en ausencia de medidas. Dentro de esos programas se establecerán los requerimientos mínimos de calificación energética que deberá cumplir la adquisición de bienes y derechos etiquetados energéticamente, y la calificación mínima de los edificios y vehículos que integran el patrimonio de las Administraciones Públicas.

Así junto a esta legislación, debemos reiterar la existencia de diversas normas autonómicas que recogen especificaciones de obligado cumplimiento de las entidades locales y así podemos citar el Decreto 42/2009, de 21 de enero, por el cual se regula la certificación energética de edificios de nueva construcción en Galicia, y la orden de 3 de septiembre de dicho año 2009, por que se regula el procedimiento la regulación y del funcionamiento del registro de certificados de dicha Comunidad, tan solo a título de ejemplo junto a todas las disposiciones enumeradas anteriormente.

Partiendo de ese ámbito, debemos destacar que las disposiciones sobre la eficiencia energética local, esto es, la capacidad normativa de las entidades locales, no habla del tipo de las normas locales, las ordenanzas por ejemplo. Aun así, sí podemos destacar la del municipio de Rivas Vaciamadrid, o los Reglamentos, distinción ésta más doctrinal que jurisprudencial, en tanto, en cuanto, los Reglamentos son normas o Disposiciones de carácter general, conforme a los artículos 51 y 52 de la LRJAPC, que se ocupan de la organización de los servicios internos y por lo tanto en cuanto al consumo energético de determinados edificios de carácter de servicio público podrían encontrarse en ese ámbito, y así podemos citar entre estos últimos el de la ciudad de Valladolid.

En cuanto a la implantación de la eficiencia energética debemos destacar que cualquier ayuntamiento puede plantearse, como hemos dicho, anteriormente su realización mediante medios propios con los límites lógicamente recogidos en los Reales Decretos Leyes 20/2011 y 20/2012, la LRSAL, y las limitaciones de la SEC 95 y la SEC 2010 utilizar medios externos, en ambos casos en la inmensa mayoría de los municipios y entidades locales, será necesario acudir a ayuda a colaboración externa. 


\section{WPS Review International on Sustainable Housing and Urban Renewal (RI-SHUR)}

Por tanto, para contar con esa colaboración, será necesario proceder a la correspondiente contratación.

Así debemos destacar como empresas de servicios energéticos lo que establece la directiva de eficiencia energética y así al respecto puede consultarse a Galera Rodrigo ${ }^{31 i}$

Así en ese sentido, el Instituto de diversificación y Ahorro Energético, viene planteando diversos modelos de pliegos, así como una recomendación de la Junta de Consultiva de Contratación Administrativa de 23 de julio de 2009, al respecto, incluso (con gran desconocimiento del concepto de servicio público previsto en el art. $26 \mathrm{RBRL}$ ) de los contratos de alumbrado.

\section{A modo de conclusión}

Así el desarrollo sostenible, o en palabras de Pérez ${ }^{32}$, sustentable ha sido indicado ya por autores como Alexander kiss e Idinah Shelton ${ }^{33}$, recogiéndose ese desarrollo, sustentable o sostenible, en palabras de Naciones Unidas como "el mejoramiento de la calidad de vida humana dentro de la capacidad de carga de los sistemas sustentadores de la vida".

\footnotetext{
${ }^{31}$ Susana Galera Rodrigo "Del ahorro de energía a la eficiencia energética .Objetivos e instrumentos de la política comunitaria" pags dentro 217 a 234 de la obra colectiva op cit Eficiencia energética y derecho...

${ }^{32}$ Efrain Pérez "Derecho ambiental” Mc Graaw Hill, Colombia, Bogotá 2000, pág.7

33 Alexander Kiss e Idinah Shelton, “ International enviromental law” 1994 supplement, Transnational publishers, Nueva York 1994, pág. 23
} 